\title{
GRATA: NOSSA HISTÓRIA, TRABALHO E DESAFIOS
}

\author{
GRATA: OUR HISTORY, WORK AND CHALLENGES
}

José Ernesto Dos Santos

Docente. Divisão de Nutrologia. Departamento de Clínica Médica. Faculdade de Medicina de Ribeirão Preto - USP

Correspondência: Divisão de Nutrologia. Departamento de Clínica Médica. Faculdade de Medicina de Ribeirão Preto - USP. Av. Bandeirantes, 3.900. CEP 14.049-900 Ribeirão Preto - SP. E-mail jedsanto@fmrp.usp.br

Dos Santos JE. GRATA: Nossa história, trabalho e desafios. Medicina (Ribeirão Preto) 2006; 39 (3): 323-6.

RESUMO: Nesta apresentação do Simpósio sobre Transtornos Alimentares são descritas as razões e a forma como o grupo de Nutrição Clínica (Nutrologia) iniciou suas atividades ambulatoriais e de enfermaria no atendimento de pacientes com transtornos alimentares. São apresentadas as situações históricas que resultaram em um grupo formado por médicos, psicólogos, psiquiatras, terapeutas ocupacionais envolvidos não só na solução do problema da desnutrição que acompanha os pacientes com anorexia e bulimia nervosas, mas também entender sua fisiopatologia e a interação dos pacientes com suas famílias. São discutidos alguns dos desafios enfrentados pelo grupo e seus projetos futuros.

Descritores: Anorexia Nervosa. Bulimia nervosa. Equipe Multidisciplinar.

Para contar nossa história, volto minha memória para o fim da década de 60 e início dos 70 . Em Ribeirão Preto tínhamos a única Faculdade de Medicina do Brasil que oferecia em seu currículo o curso de Nutrição em Clínica Médica. Esse pioneirismo se iniciara em 1955 com a contratação de um jovem médico, o Prof.Dr. José Eduardo Dutra de Oliveira, recém egresso de estágios nos Departamentos de Nutrição das Universidades Tulane, de Cincinnati e Vanderbilt nos Estados Unidos. Esse curso denominou-se posteriormente de Nutrição Clínica e mais tarde Nutrologia, nome sugerido pelo próprio Prof. Dutra de Oliveira ${ }^{1}$.

Outras tentativas de ensino de Nutrição a estudantes de Medicina em outras faculdades do Brasil e do exterior já haviam sido feitas, mas sem o sucesso de Ribeirão Preto. Credita-se esse sucesso a capacidade de liderança do Prof. Dutra e ao fato que o ensino de Nutrição fragmentado em vários Departamentos (como era praticado então) tornava o curso desinteressante, impedindo a identificação de Nutrição como unidade de ensino e uma especialidade médica.
Mesmo com todas essas características, até 1971 na Faculdade de Medicina de Ribeirão Preto não existia um ambulatório de Nutrição. A sua criação parecia insana num sistema que focalizava a sua atenção somente às especialidades clássicas como Nefrologia, Cardiologia, Hematologia etc.

A partir de 1971 começamos, juntamente com o nutricionista Pedro Roberto Venezziano (até então o único nutricionista do Hospital das Clínicas da Faculdade de Medicina de Ribeirão Preto-USP (HC-FMRPUSP), um hospital então com cerca de 400 leitos) e com o apoio e colaboração irrestritos do Professor Dutra, a tentativa de identificar essa unidade de ensino com enfermarias, ambulatórios e laboratório clínico.

Para enfermaria conseguimos autorização do Departamento para que dois leitos da ala de pacientes do sexo masculino e dois leitos da ala do sexo feminino das enfermarias de Clínica Geral (coordenadas pelo Prof. Renato Alves de Godoy e Prof. José Augusto Laus Filho) fossem alocados para a disciplina de $\mathrm{Nu}-$ trição, que nessa época, durante o período de chefia do Departamento pelo Prof. Cássio Bottura havia, jun- 
tamente com a disciplina de Imunologia Clínica, adquirido o status de disciplina na estrutura organizacional e didática do Departamento.

Vencido esse primeiro problema e dada à impossibilidade de criarmos um Ambulatório de Nutrição, pois todos os espaços e dias do ambulatório (conhecido então como "as mangueiras") estavam tomados por outras especialidades, fixamos a nossa participação em um dos ambulatórios (às quintas-feiras) de Clínica Geral do Departamento. O Departamento tinha três tardes dedicadas ao que se denominava de Ambulatório Geral, às segundas, terças e quintas-feiras. Esses ambulatórios eram supervisionados em sistema de rodízio por todos os docentes do Departamento. Essa atitude foi até que bem vista pelos demais colegas que dividiam as tarefas do Ambulatório Geral. Passamos a ter todas as quintas-feiras nosso ambulatório (de Clínica Geral) para atender pacientes juntamente com quintoanistas de Medicina. Como é lógico de se imaginar, com a fixação de dois profissionais interessados em Nutrição no ambulatório, esse passou a receber um grupo de pacientes que nenhuma especialidade clínica se interessava em tratar, os obesos. Esse foi o início do Ambulatório de Nutrologia da FMRP-USP.

Nessa época começava também a surgir em nosso meio um grupo de doenças com as quais eu já havia tomado contato como quintoanista de Medicina, os distúrbios de comportamento alimentar, especialmente anorexia nervosa e bulimia nervosa. Interessei-me particularmente por esse problema pelo impacto que ele provocou-me quando atendi a primeira paciente com anorexia nervosa em 1969. Era uma paciente com cerca de 15 anos internada periodicamente na Enfermaria Geral do Prof. Godoy, a pedido da professora de Psiquiatria Honna Tahim Mantovani, para repor por via parenteral as suas necessidades nutricionais e especialmente de cálcio. Chamou-me atenção a "ilógica" de uma pessoa deixar de se alimentar voluntariamente e a freqüente presença de hipercolesterolemia nas anoréxicas nervosas.

$\mathrm{O}$ atendimento a pacientes com anorexia nervosa pela Divisão de Nutrologia do Departamento de Clínica Médica ampliou-se a partir de 1980 (com meu retorno do período de pós-doutorado) e deveu-se inicialmente ao fato deles se apresentarem com desnutrição. Os métodos terapêuticos para restabelecimento de seus estados nutricionais já eram de domínio do grupo de Nutrologia do HC. No início dos anos 80 quando o GRATA (Grupo de Assistência aos Transtornos Alimentares), chamado inicialmente por iniciativa do
Dr. Paulo César Monteiro dos Santos de GEED (Grupo de Estudos dos Distúrbios da Conduta Alimentar) teve seu embrião formado. Se analisarmos sob ponto de vista clínico-nutricional, podemos dizer que fomos muito eficientes em nossa atuação. Nos 24 anos que nos separam do atendimento da primeira paciente trabalhamos com mais de 180 pacientes e sobre o ponto de vista nutricional, mais de $90 \%$ delas deixaram de ser desnutridas, e observamos infelizmente três óbitos em uma estatística universal que estima a mortalidade em 5 a $8 \%$.

Para um grupo de Nutrição pergunta-se: isso não basta? Não. A tentativa de uma comunicação integral com esses pacientes nos fez compreender que deixar de comer ou comer de maneira descontrolada e em seguida assumir atitudes compensadoras como vômito provocado ou ingestão de laxantes, sem que causas orgânicas sejam diagnosticadas, não representa uma doença, mas um sintoma ou um sinal clínico de outra etiologia que não tínhamos o acesso a seu diagnostico e investigação pelos métodos que dispúnhamos e que dispomos até o momento.

A necessidade da formação de uma equipe multidisciplinar para o atendimento desses pacientes também surgiu de uma observação simples que, no entanto, para a ela chegarmos precisamos da atitude nem sempre confortável de deixar nossas vestes de onipotência e onisciência para enxergarmos que quando um paciente deixa de se alimentar, sem uma causa orgânica, ele não o faz por desejo consciente próprio, mas por outras causas, que a orientação nutricional tradicional e isolada não tem eficácia e eficiência desejáveis para o seu tratamento.

A terapia nutricional clássica ou o suporte nutricional enteral ou parenteral são fundamentais para tratamento sintomatológico, orgânico, porém não são panacéias para o tratamento integral dos pacientes com distúrbios de comportamento alimentar. Podemos inclusive comparar esta conduta como a orientação "pare de beber" a um alcoólico crônico ou "coma menos" e "faça exercícios diários" a um obeso. A sensação de impotência provocada pelos anoréxicos nervosos nos induz a utilizarmos com mais freqüência esses métodos de suporte artificial em alguns momentos com o objetivo de preservar suas vidas.

Nos permitimos questionar como abordar o tratamento de um adolescente que se apresenta desnutrido e com aspecto esquelético e temos a percepção, depois de algumas consultas, que seu poder sobre seus pais é ser persistente no "não" quando eles pedem para ele se alimentar. 
A duvida que se seguiu foi a mais óbvia, ou seja, sendo esses pacientes portadores de um conjunto de sinais e sintomas que se identificam com doença psiquiátrica ou psicossomática seríamos nós, de uma Divisão de Nutrologia de um Departamento de Clínica Médica que deveríamos essa abordagem ampla?

Pensamos que sim, pois qualquer serviço de atendimento em um hospital universitário, pela sua própria natureza, deve ter "limites infinitos", ou o "limite que nossos sonhos e curiosidade permitem alcançar”. A universidade é o local ideal para darmos liberdade às buscas que supram nossas insatisfações. Sobre esse aspecto, Santiago Kovadloff ${ }^{2}$, filósofo argentino contemporâneo, refere em sua recente palestra na abertura do Congresso da Internacional de Psicanálise no Rio de Janeiro, que "devemos considerar que na formação do Universitário, em sentido rigoroso, sem contar com um conhecimento rigorosamente comprovado, que o autoriza a agir em área especifica, define-se por uma visão privilegiada do conjunto que ultrapassa o território concreto no qual se desenvolveu como especialista". Continuando, Kovadloff enfatiza: A palavra universitário, na sua acepção eminente, traduz, como se sabe, a idéia de universalidade, de uma comunidade de valores ativos e discerníveis em cada expressão singular do conhecimento e da vida cotidiana do corpo social .

Foi provavelmente com esse sentimento que os primeiros passos para tentarmos universalizar o conhecimento e o atendimento de portadores de distúrbios de comportamento alimentar foram dados. Associamo-nos inicialmente com um psiquiatra com formação em Clínica Médica, o Dr. Paulo César Monteiro dos Santos, e posteriormente a nutricionista Rosane Pilot Pessa Ribeiro. Foi com certeza o primeiro grupo multidisciplinar para atendimento de transtornos de comportamento alimentar. ${ }^{3,4} \mathrm{~A}$ associação com a nutricionista foi óbvia e indiscutível, enquanto que a participação de um psiquiatra no grupo gerou uma série de questionamentos e dúvidas em um Departamento de Clínica Médica nos "distantes" anos 80 do século passado. É interessante se observar que nossa investigação de pacientes com hipercolesterolemia familiar com métodos de biologia molecular ${ }^{5,6}$ sempre foi aprovada, embora tanto a associação com um psiquiatra quanto com um biólogo molecular trazem em sua essência a busca do entendimento das doenças.

A colaboração com profissional da área psicológica trouxe, como era de se prever, progressos e passamos a entender, ou melhor, ouvir e enxergar um ou- tro plano da comunicação com o doente e a utilizarmos outros parâmetros, que não somente o peso, as pregas cutâneas, os níveis séricos de vitaminas, para avaliarmos a sua evolução. Incluímos em nossa leitura outras referências bibliográficas, passamos a conhecer outros autores e tentamos entender outras linguagens.

O trabalho multidisciplinar, embora muito fácil de ser falado, envolve uma série de mudanças de comportamento que nem sempre temos permeabilidade e habilidade para conseguir. Temos de início que abandonar a onipotência de médico, para entendermos uma nova linguagem e acima de tudo sermos abertos e disponíveis para aceitarmos outras sugestões, orientações e procedimentos terapêuticos que não são de nosso domínio.

As conseqüências da formação de um grupo com nutricionista e psiquiatra foram os melhores resultados do tratamento, o baixíssimo índice de complicações e a tranqüilidade de estarmos trilhando um caminho Universitário. Tivemos a oportunidade de como grupo formar outros profissionais que tiveram possibilidade de conviver em um grupo que se respeita e que tem permeabilidade para adquirir novas habilidades.

O pensamento critico, os olhos abertos e os ouvidos permeáveis (em outras palavras a ausência de onipotência) são sempre as grandes alavancas para essas mudanças. Vale nesse momento lembrar a música de Ivan Lins e Vitor Martins que norteou muitas de nossas ações e que consideramos fundamental para harmonia de um grupo interdisciplinar e interprofissional:

Daquilo que eu sei

Nem tudo me deu clareza

Nem tudo foi permitido

Nem tudo me deu certeza

Daquilo que eu sei

Nem tudo foi proibido

Nem tudo me foi possível

Nem tudo me foi concebido

Não fechei os olhos

Não tapei os ouvidos

Cheirei, toquei, provei.

$\mathrm{Ah}$ ! Eu usei todos os sentidos

Só não lavei as mãos

E é por isso que eu me sinto

Cada vez mais limpo

Cada vez mais limpo. 
Seguindo essa linha, fizemos outros contatos com profissionais de outros Departamentos da FMRP-USP e do Hospital das Clínicas e outras Unidades do Campus de Ribeirão Preto-USP nos mostraram, entre outras possibilidades e necessidades, a importância de outras abordagens, como o atendimento dos pacientes em grupos e de suas famílias. A chegada do psicólogo Manoel Antônio dos Santos trouxe uma nova visão: passamos a trabalhar com os pacientes em grupos e atender seus familiares. Posteriormente, nos associamos a diferentes linhas de pensamento, psicanalistas, terapeutas ocupacionais e, não tenho dúvida, sempre que existir base racional científica o grupo estará sempre aberto para ouvir e tentar entender outros profissionais que queiram trabalhar na exaustiva, porém confortadora tarefa de tratar o paciente com distúrbio de comportamento alimentar. Outro ganho inestimável que tivemos foi a possibilidade de formarmos residentes com capacidade de ouvir, entender e se comunicar com profissionais de outras áreas de conhecimento, habilidade essa tão necessária nos tempos atuais.

Existem muitos desafios a serem vencidos.
Poderíamos adentrar por aqueles de natureza material que afetam profundamente a velocidade e a eficiência de nosso trabalho, porém acho que mais prioritariamente precisamos de:

1- desenvolver métodos de motivação para que profissionais de diferentes áreas, com formações tão diversas possam se comunicar, se entender e continuar especialistas em suas respectivas áreas de formação;

2- oferecer supervisão adequada para equiparmos mentalmente esses profissionais para seu trabalho. (ver artigo de Borges dos Santos neste Simpósio, Capítulo XV).

Passados mais de 24 anos e com mais de 180 pacientes atendidos não temos duvidas que a criação formal de um grupo, o GRATA é a materialização dessas idéias. A qualidade do atendimento ao paciente com distúrbio de comportamento alimentar, dos profissionais que formamos e, acima de tudo, a tentativa do entendimento universalizado desse grupo de doenças será a síntese de sua saúde e de sua integração.

Dos Santos JE. GRATA: our history, work and challenges. Medicina (Ribeirão Preto) 2006; 39 (3): 323-6.

ABSTRACT: In this paper the author describes the rational and the way how a Clinical Nutrition group (Nutrology) begins in 1980 outpatient and inpatient care of patients with eating disorders. Historical and political aspects are describing resulting in the present group (GRATA). Physicians, psychologists, psychiatrics and occupational therapists are involved in the nutritional care and attention to other problems of the anorexic and bulimic patient including the family. It is discussed same challenges that the group is involved and future projects.

Keywords: Anorexia Nervosa. Bulimia Nervosa. Multidisciplinary Team.

\section{REFERÊNCIAS}

1 - Dutra de Oliveira JE. Nutrition as a medical subspecialty. Am J Clin Nutr 1975; 28 (7): 674.

2 - Kovadloff S. A construção do presente: feições filosóficas do conceito de trauma. In: França MOAF, org. Trauma psíquico. Uma leitura psicanalítica e filosófica da cultura moderna. São Paulo: SBPSP; 2005.

3 - Monteiro dos Santos PC, lucif Jr. N, Ferronato MA, Dutra de Oliveira JE, Santos JE. Anorexia nervosa: uma revisão clínica de 12 casos. Rev Paul Med 1986; 104(5):240-6.
4 - Monteiro dos Santos PC, lucif Jr. N, Pessa RP, Santos JE. Anorexia nervosa e bulimia: aspectos psicopatológicos, demográficos, diagnósticos e clínicos. Rev Bras Psiq 1988; 10(2):35-41.

5 - Figueiredo MS, Santos JE, Alberto FA, Zago MA. High frequency of the Lebanese allele of LDLr gene amongst Brazilian patients with hypercholesterolemia. J Med Genet 1992; 29: 813-5.

6 - Alberto FA, Figueiredo MS, Zago MA, Araujo AG, Santos JE. The Lebanese mutation as an important cause of familial hypercholesterolemia in Brazil. Braz J Med Biol Res 1999; 32 (6):739-45. 